\title{
Comparison of Solid-Phase Radioimmunoassay and Competitive Protein Binding Method for Post- dexamethasone Cortisol Levels in Psychiatric Patients
}

\author{
Timothy E. Wilens, George W. Arana, Ross J. Baldessarini, and Cornelia \\ Cremens
}

Received September 27, 1982; revised version received December 27, 1982; accepted Januarv 18,1983 .

\begin{abstract}
Results obtained by competitive protein binding assay (PBA) and a solid-phase radioimmunoassay (RIA) for cortisol were compared in 157 samples from 100 psychiatric paticnts given a dexamethasone suppression test (DST). Cortisol levels in plasma samples obtained at 8:00 a.m. or 4:00 p.m. the day following $1.0 \mathrm{mg}$ dexamethasone orally at bedtime ranged from 0 to $30 \mu \mathrm{g} / \mathrm{dl}$ and correlated closely $(r=0.96)$. However, RIA gave values that were consistently and significantly lower (average $=8.9 \%$ ) than those obtained by PBA. When samples were further assayed by a specific RIA for corticosterone, there was a strong correlation between cortisol and corticosterone RIA values $(r=0.79)$, and corticosterone (7.8\% of cortisol levels) accounted for most of the difference between PBA and RIA for cortisol. The relationship between results of the two cortisol assay methods can be expressed (in $\mu \mathrm{g} / \mathrm{dl}$ ) by the equation: $\mathrm{RIA}=0.92(\mathrm{PBA})-0.10$, based on findings obtained in a separate analysis of 127 samples with cortisol values in the $0-10 \mu \mathrm{g} / \mathrm{dl}$ range, critical to the valid interpretation of the DST in melancholia. A reported criterion of a "positive" DST in psychiatry, of plasma cortisol of $\geqslant 5.0 \mu \mathrm{g} / \mathrm{dl}$ has been suggested by use of a PBA. Use of the present RIA required that this value be adjusted downward, at least to $4.5 \mu \mathrm{g} / \mathrm{dl}$; application of this criterion increased the clinical sensitivity of the DST by $10 \%$. We urge local, independent verification of criteria to define the DST as "positive" in each laboratory and with each method of assay.
\end{abstract}

Key Words. Cortisol assays, dexamethasone suppression test, depression.

To date, plasma cortisol (hydrocortisone, 17-hydroxycorticosterone, or compound F) has been measured by the following methods: fluorometric, double-isotope derivative, competitive protein binding assay (PBA), and radioimmunoassay (RIA). The competitive protein binding method (Murphy, 1967) requires only small blood samples, is sensitive, inexpensive, and simple. Human cortisol binding globulin (transcortin), the selective hinding protein used by this method, is not specific for cortisol, as it also

\footnotetext{
Timothy E. Wilens was a predoctoral rescarch assistant at Harvard Medical School from the University of Michigan School of Medicine. George W. Arana, M.D., is Assistant Professor and Ross J. Baldessarini, M.D., is Professor of Psychiatry, Department of Psychiatry, Harvard Medical School. Cornelia Cremens, M.T., is Coordinator of Clinical Laboratory Services, McLean Hospital. (Reprint requests to Dr. G.W. Arana, Mailman Research Center, McLean Huspital, 115 Mill St., Belmont, MA 02178, USA.)
} 
binds corticosterone, 11-deoxycortisol, cortisone, and other steroids; accordingly, this technique often yields somewhat higher values for cortisol than do other more selective methods (Farmer and Pierce, 1974; Jiang et al., 1975; Thijssen et al., 1980; Ritchie and Carroll, 1981). Because of the generally greater specificity and excellent sensitivity of many RIA techniques, they have become an increasingly accepted method for mcasurcment of cortisol for clinical purposes (Kumar et al., 1976; Brock ct al., 1978; Thijssen et al., 1980). One system of RIA, a solid-phase technique which uses ${ }^{125} \mathrm{I}$-labeled cortisol and is marketed by Scientific Products, is used to measure cortisol levels here and in many other hospital laboratories.

Numerous efforts have been made to apply endocrinological methods to aid in the diagnosis of major endogenomorphic depression (melancholia) (Baldessarini, 1983). These include assays of cortisol, notably in the dexamethasone suppression test (DST) (Carroll et al., 1981; Carroll, 1982a, 1982b). Dexamethasone, a synthetic glucocorticoid, suppresses limbic-hypothalamic-pituitary-adrenocortical activity, presumably by mimicking physiologic feedback inhibition of the release of pituitary adrenocorticotropic hormone (ACTH) through the central nervous system (CNS). When oral dexamethasone $(1.0 \mathrm{mg})$ is given at 11:00 or 11:30 p.m., normal subjects and psychiatric controls maintain plasma cortisol suppression below $5.0 \mu \mathrm{g} / \mathrm{dl}$ for 24 hours or longer, as assessed by a PBA method (Carroll et al., 1981). Those psychiatric patients who have higher plasma cortisol levels or "escape" dexamethasone suppression wit hin 24 hours are considered to have an abnormality of CNS-pituitary mechanisms that regulate $\mathrm{ACTH}$, and thus adrenal glucocorticoid secretion. It has been proposed that such dysregulation of cortisol secretion may be selective for melancholia (Carroll et al., 1981), although the test is being found to be "positive" in an increasing range of conditions (Arana et al., 1982; Finklestein et al., 1982).

Recently reported criterion values that define a "positive" DST by plasma or scrum cortisol levels $\geqslant 5 \mu \mathrm{g} / \mathrm{dl}$ have been proposed, based on use of a competitive protein binding assay (Carroll et al., 1981). Few reports have directly compared the PBA and increasingly common RIA methods in the range reported to be critical in differentiating melancholia from other psychiatric illesses (Kumar et al., 1976; Brock et al., 1978), and none has involved a psychiatric population. Since several previous studies already cited suggest that cortisol values obtained by PBA may be somewhat higher than those obtained using RIA, there is a potential for a "false negative" interpretation of the DST with a more specific RIA. Thus, it is of interest to compare the two commonly used assay methods directly in a psychiatric population. Of particular clinical interest is the range believed to be critical for the DST in depression $(1-10 \mu \mathrm{g} / \mathrm{dl})$, as well as higher levels as may be encountered with the DST in endocrinological disorders such as Cushing's syndrome and in some cases of depression (Liddle, 1960).

\section{Methods}

Competitive Protein Binding (PBA) Assay. Cortisol in human plasma was assayed using modifications of the PBA assay of Murphy (1967). [1.2- $\left.{ }^{3} \mathrm{H}\right]$ Corticosterone (40 Ci/ mmole) was obtained from New England Nuclear (Boston, MA). Without further purification, a $250 \mu \mathrm{Ci}$ vial of this labeled steroid was diluted to $25.0 \mathrm{ml}$ with absolute ethanol (redistilled. IMC Chemical, Terre Haute, IN) and stored at $-20^{\circ} \mathrm{C}$. A stock solution of human cortisol-binding 
globulin (transcortin) was prepared by adding $1.0 \mathrm{ml}$ of the diluted ${ }^{3} \mathrm{H}$-corticosterone to $1.5 \mathrm{ml}$ ethanol, $200 \mathrm{ml}$ distilled water, and $5.0 \mathrm{ml}$ of pooled normal human plasma - all adjusted to 250 $\mathrm{ml}$ with distilled water (final transcortin solution $=2 \%, \mathrm{w} / \mathrm{v}$ ). Just before use, an amount sufficient for an assay was allowed to warm to room temperature. Standard solutions of authentic unlabeled cortisol (Sigma Chemical, St. Louis, MO) in absolute ethanol were prepared by serial dilutions to provide final concentrations of $0.0 .5,1,2,5,10$ and $20 \mathrm{ng} / 0.2 \mathrm{ml}$, all stored at $-20^{\circ} \mathrm{C}$. Standard plots were routinely prepared for each assay using triplicate samples of the authentic cortisol solutions. To $15 \times 85 \mathrm{~mm}$ disposable borosilicate glass tubes (Scientific Products, McGaw Park, IL), $0.5 \mathrm{ml}$ samples of human plasma were extracted into $1.0 \mathrm{ml}$ ethanol, vortexed, and centrifuged at $2,000 \mathrm{~g}$ for 12 minutes; $0.2 \mathrm{ml}$ portions of the ethanolcortisol phase were aliquoted in duplicate. Control samples were routinely included which assayed pooled normal human plasma (Blood Bank, Massachusetts General Hospital), treated as above except that $0.1,0.2$, or $0.3 \mathrm{ml}$ of the extract of control plasma was added to duplicate tubes. All tubes containing authentic cortisol samples or control plasma specimens were then dried under a stream of air in a $45^{\circ} \mathrm{C}$ water bath.

The PBA assay was performed as described by Murphy (1967) with Florisil (Fischer Scientific, Fair Lawn, NJ) as the adsorbant to remove unbound ${ }^{3} \mathrm{H}$-steroid molccules. Briefly, $1.0 \mathrm{ml}$ of the diluted ${ }^{3} \mathrm{H}$-corticosterone solution already described was added to each assay tube, which was immediately vortexed and incubated at $45^{\circ} \mathrm{C}$ for 10 minutes. Samples were removed to an ice bath for 20 minutes. Preweighed Florisil $(40 \mathrm{mg})$ was added to each tube; tubes were shaken at room temperature for 2 minutes, returned to the ice bath for 10 minutes and centrifuged at $2,000 \mathrm{~g}$ for 6 minutes. A $0.5 \mathrm{ml}$ aliquot of the upper phase (containing ${ }^{3} \mathrm{H}$-corticosterone bound to transcortin) was removed to polypropylene scintillation counting vials (Research Products International, Mt. Prospect, IL) containing $5.0 \mathrm{ml}$ of Liquiscint fluid (National Diagnostics, Somerville, NJ), and counted in a Packard 3320 scintillation spectrometer (Packard Instruments, Bedford, MA). Radioactivity counts were then accumulated and a standard plot was constructed as cortisol concentration per tube vs. the corresponding time necessary to attain 20.000 counts per minute (CPM), sufficient to produce a counting error of $< \pm 1 \%$.

Solid-Phase Radioimmunoassay (RIA). Plasma cortisol also was determined by a solidphase radioimmunoassay kit (Immu-Trace Cortisol R.I.A.) marketed by Scientific Products (McGaw Park, IL) and produced by Ventrex Laboratories (Portland, ME). Included in the kit are inert "sticks" impregnated with an antibody to cortisol, assay tubes, diluting buffer, wash

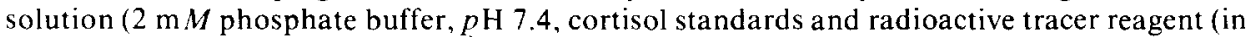

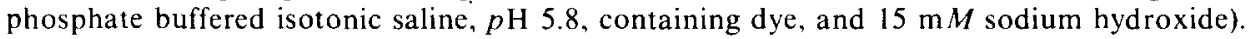
Tubes were prepared in duplicate with $0.01 \mathrm{ml}$ of either standard solutions of authentic cortisol, control pooled normal human plasma, or patient plasma samples. Then, $1.0 \mathrm{ml}$ of the buffered tracer reagent was added to each tube, vortexed briefly, and an antibody "stick" was inserted. The tubes were incubated at room temperature for 30 minutes; the reaction was stopped by inverting all tubes and washing with $2.5 \mathrm{ml}$ of wash solution. The tubes were reinverted; their edges were blotted, and they were placed (including antibody sticks) in a gamma scintillation spectrometer (Packard Instruments, Bedford, MA) to count the bound ${ }^{125}$ I-cortisol for I minute. The standard curve obtained in each assay was linearized by plotting (as a percentage) the ratio of CPM bound with standard:CPM bound with blank, vs. the log of the concentration of authentic cortisol standards.

A similar, specific RIA was used to assay corticosterone in the same serum samples. This assay was based on materials obtained from Endocrine Sciences Labs. (Tarzana, CA), and extraction of samples with hexane and benzene to remove potentially interfering steroids (such as cortisol and progesterone), as described in detail elsewhere (Wilens et al., in press).

Patient Samples. We studied 157 plasma samples from 132 tests performed between October 1981 and July 1982 in 100 patients of the McLean Hospital. Records of all cases were reviewed to eliminate any patients being treated with medications (i.e., steroids) known to interfere with cortisol determinations. DSM-III (American Psychiatric Association, 1980) diagnoses of this 
patient population included bipolar illness, melancholia, schizophrenia, and atypical psychosis. All 100 patients had dexamethasone suppression tests (DSTs) administered by giving $1.0 \mathrm{mg}$ of dexamethasone orally at 11:30 p.m.; blood samples were obtained the next day in heparinized glass tubes, either at both 8:00 a.m. and 4:00 p.m. (50 samples) or only at 4:00 p.m. (107 samples), according to Carroll et al. (1981; Carroll, 1982b).

\section{Results}

Comparison of Cross-Reactions of Assays With Steroids (Table 1). The PBA method, using ${ }^{3} \mathrm{H}$-corticosterone as the index ligand and a cortisol binding globulin, tanscortin, as the selective binding agent, shows significant cross-reactions with 11-deoxycortisol, corticosterone, and cortisone (100\%), and weaker reactions with prednisone and prednisolone (20\% and $15 \%$, respectively). The RIA, using a specific antibody to cortisol and ${ }^{125} \mathrm{I}$-cortisol as ligand, shows greater specificity, with appreciable cross-reactions noted only with prednisolone, 11-deoxycortisol, and prednisone $(44.9 \%, 15.5 \%$, and $4.1 \%$, respectively), all of which are uncommon in normal human blood.

\begin{tabular}{|c|c|c|}
\hline \multirow{2}{*}{ Compound 1} & \multicolumn{2}{|c|}{ Percent cross-reaction 2} \\
\hline & PBA $^{3}$ & RIA4 \\
\hline Cortisol & 100.0 & 100.0 \\
\hline Corticosterone & 100.0 & 1.5 \\
\hline 11-Deoxycortisol & 100.0 & 15.5 \\
\hline Cortisone & 100.0 & 1.7 \\
\hline Prednisone & 20.0 & 4.1 \\
\hline Prednisolone & 15.0 & 44.9 \\
\hline Dexamethasone & 0.0 & 0.9 \\
\hline \multicolumn{3}{|c|}{$\begin{array}{l}\text { 1. Note that of these steroids, except for cortisol, only cortic } \\
\text { lo be encourlered in normal human plasma in appreciab } \\
\text { 1979). } \\
\text { 2. Effect relative to an equal weight of cortisol in percent. } \\
\text { 3. Murphy (1967). } \\
\text { 4. Scientific Products Technical Report (1981). }\end{array}$} \\
\hline
\end{tabular}

Comparison of Results With PBA and RIA for Cortisol. Cortisol concentrations of three different dilutions of pooled normal human plasma were determined in 10 assays by both methods. Values of inter-and intra-assay coefficients of variation were calculated (Rodbard, 1974). An intra-assay coefficient of variation was calculated at the mean ratio of SD to the mean of six replicate determinations carried out in each of 10 independent assays of pooled human serum. An interassay coefficient was similarly derived for the 10 independent assays performed on different days. The PBA yielded less interassay variability than the RIA ( $7.1 \%$ vs. $11.3 \%$, respectively). The PBA and RIA were similar, however, with respect to intra-assay coefficients of variation $(6.2 \%$ and $5.8 \%$, respectively). 
In Fig. $1 \mathrm{~A}$, results for 157 individual specimens (from 100 patients) assayed by both PBA and RIA are compared. The mean $( \pm$ SD) for these samples by PBA was $5.02 \pm$ 5.51 , and by RIA was $4.61 \pm 5.51 \mu \mathrm{g} / \mathrm{dl}$ (difference $=8.9 \%$, which is significant by $t$ test of related means, $p<0.005$ ). A close correlation was found between the results of the two assay methods $(r=0.955, p<0.001$; slope was $0.951 ; \mathrm{y}$-intercept $=-0.166$; Fig. $1 \mathrm{~A})$. While the difference in results between the two methods was not large, it appeared to be consistent and significant: the level by PBA was higher in 104 of 156 assays in which a difference occurred $(66.7 \%$ of cases, $p<0.001$ by sign test). The difference in slope of the observed Pearson product moment regression line from a theoretical, ideal slope of 1.0 was also statistically significant (by $t$ test for slopes of lines, according to Kreyszig, 1970, and Zar, 1974, $p<0.05$ ). An expanded view is provided in Fig. I B for results of PBA vs. RIA between 0 and $10 \mu \mathrm{g} / \mathrm{dl}(n=127)$-a crucial range for interpretation of the DST for melancholia for which a criterion level of $\geqslant 5.0 \mu \mathrm{g} / \mathrm{dl}$ has been suggested, based on a PBA (Carroll et al., 1981). These results again indicate a close correlation $(r=0.926)$, but somewhat greater deviation toward the PBA $($ slope $=$ 0.922 , y-intercept $=-0.098$ ), and suggest that the criterion for a "positive" or abnormal DST most comparable to a value of $5.0 \mu \mathrm{g} / \mathrm{dl}$ by PBA should be adjusted downward to $4.5 \mu \mathrm{g} / \mathrm{dl}$ when the present RIA method for plasma cortisol is employed (Fig. 1).

\section{Fig. 1. Comparison of postdexamethasone plasma cortisol determinations (in $\mu \mathrm{g} / \mathrm{d}$ l) by solid-phase radioimmunoassay $(\mathrm{R} \mid \mathrm{A}=\mathbf{y})$ vs. competitive pro- tein binding assay (PBA $=x)$}

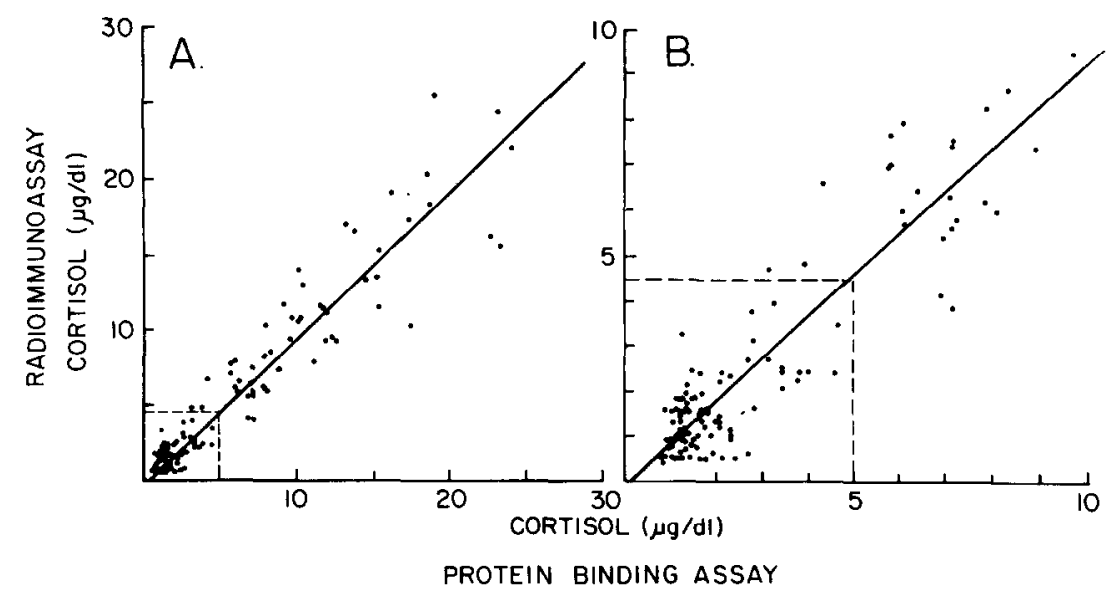

A. Computed linear regression analysis yielded: $r=0.955$, slope $=0.951$, and $y$-intercept $=-0.166(n=157$ samples!.

B. Detailed comparison of results when both assay methods yield cortisol levels of 0 to $10.0 \mu \mathrm{g} / \mathrm{dl}(\mathrm{n}=127$ samples, $r=0.926$, slope $=0.922$, and $y$-intercept $=-0.098$ ). Note the critical value of $5.0 \mu \mathrm{g} / \mathrm{dl}$ defined by the PBA method is apparently equivalent to $4.5 \mu \mathrm{g} / \mathrm{dl}$ by RIA. 
The assay of corticosterone by RIA revealed a mean value $( \pm \mathrm{SD})$ of $2.72 \pm 3.07$ $\mu \mathrm{g} / \mathrm{dl}$ ( $n=136$ samples). These values were correlated closely with RIA levels of cortisol in 136 of the same blood specimens $(r=0.794, n=136, p<0.001)$. The mean ( \pm $\mathrm{SD})$ ratio of corticosterone to cortisol by RIAs was $7.78 \pm 6.00 \%(n=136)$.

\section{Discussion}

The PBA method detects not only cortisol (17-hydroxycorticosterone), the predominant circulating adrenal glucocorticosteroid in man (Murphy, 1967), but also crossreacts with less prevalent steroids such as 11 -deoxycortisol, cortisone, corticosterone, and, to a lesser extent, prednisone and prednisolone (Table 1). Of the less prevalent steroids, only corticosterone is believed to be present in human plasma in appreciable concentrations (reportedly ca. 4\% those of cortisol) (Krieger, 1979) so that the nearly 9\% discrepancy between results of a PBA and a more specific RIA used here (Fig. 1) evidently is at lcast partly accounted for by cross-reaction of corticosterone in the binding assay (Table 1). Moreover, when a direct estimate of the possible contribution of corticosterone was made by RIA analysis for corticosterone in many of the present samples, the results indicated that corticosterone values were closely correlated with those of cortisol $(r=0.79)$ and averaged $7.8 \%$ of the values for cortisol obtained by PBA. The present findings of a somewhat higher value for plasma cortisol by a PBA method than an RIA method are consistent with previous comparisons of similar PBA and RIA assays (Farmer and Pierce, 1974; Jiang et al., 1975; Brock et al., 1978; Thijssen et al., 1980; Ritchie and Carroll, 1981). However, in these previous studies, most of the plasma cortisol values being compared ranged from 10 to $30 \mu \mathrm{g} / \mathrm{dl}$ and involved fewer than 40 samples from medical patients.

In the present study we analyzed 157 plasma specimens obtained at 8:00 a.m. and 4:00 p.m., or only at 4:00 p.m., on the day following $1 \mathrm{mg}$ of dexamethasone at bedtime in 100 psychiatric patients by both PBA and RIA methods; of these, 127 samples yielded apparent cortisol levels below $10 \mu \mathrm{g} / \mathrm{dl}$, as determined by both methods. The equation we calculated by computed linear analysis for these 127 most pertinent samples was: $\mathrm{RIA}=0.92(\mathrm{PBA})-0.10($ Fig. $1 \mathrm{~B})$. Comparable equations reported by others and based largely on levels above $10 \mu \mathrm{g} / \mathrm{dl}$ were: $\mathrm{RIA}=0.72(\mathrm{PBA})-0.06 \mu \mathrm{g} / \mathrm{dl}$ (Farmer and Pierce, 1974) and RIA $=0.92(\mathrm{PBA})+0.05 \mu \mathrm{g} / \mathrm{dl}$ (Brock et al., 1978). The sensitivity of solid-phase RIA used in the study of Brock et al. $(0.5 \mu \mathrm{g} / \mathrm{dl})$ is only slightly lower than that of the PBA $(0.2 \mu \mathrm{g} / \mathrm{dl})$ (Murphy, 1967).

Because of the importance of the criterion value recommended for the interpretation of the DST, the use of the value of $5.0 \mu \mathrm{g} / \mathrm{dl}$ proposed from data obtained by PBA (Carroll et al., 1981) should evidently be adjusted to an RIA value of $4.5 \mu \mathrm{g} / \mathrm{dl}$ with the RIA which we employed. "Questionable" or "borderline" values of cortisol of 3.5 to 5.0 by PBA should, likewise, evidently be revised to about 3.0 to $4.5 \mu \mathrm{g} / \mathrm{dl}$ for our RIA results. The downward adjustment of the DST criterion level to $\geqslant 4.5 \mu \mathrm{g} / \mathrm{dl}$ for the present RIA method, albeit slight, in this study led to the reconsideration of five previously defined "negative" DSTs as "borderline" abnormal and, more importantly, two previously questionable DSTs to be reinterpreted as positive or abnormal tests. Both of the latter cases were found (independent of the assessment of the RIA criterion) to meet $D S M-I I I$ criteria for major depression (one was melancholic; the 
other was in a mixed manic depressive state and yielded a strongly positive DST on repeat testing). This change in criterion for the results with our RIA thus led to an increase in sensitivity of the DST in this population of $10 \%$. It is of interest that Rush ct al. (1982) independently came to a similar conclusion based on an empirical decision to maximize the sensitivity of a DST procedure that used an RIA for cortisol, and recommended $4.0 \mu \mathrm{g} / \mathrm{dl}$ as an appropriate cut-off value, as Carroll (1982a) has also suggested for RIA-based DST. Other investigators have also noted not only a tendency for some RIA assays of cortisol to yield lower values than PBA assays, but for others to yield equal or even higher values; that is, there is considerable variation between laboratories and specific antibody preparations (Dr. H.Y. Meltzer, personal communication, December, 1982). Accordingly, we conclude from the present results that the criterion for a "positive" DST may need to be revised downward when a more specific assay of cortisol than used previously is employed. More generally, we suggest that standards for interpretation of the DST require critical evaluation with each method or laboratory employed in the assay of cortisol.

Acknowledgments. This research was supported in part by a McLean Hospital research fellowship (TEW), an NIH BRSG grant RR-05484 to the McLean Hospital (GWA), an award from the Scottish Rite Schizophrenia Foundation. Northern Masonic Jurisdiction (GWA), an NIMH research grant MH-31154 and Clinical Center Award MH-36224 to McLean Hospital. and a Research Career Scientist $\mathrm{A}$ ward MH-47370 (RJB). We are grateful to James Ritchie, Psychiatric Research Institute, University of Michigan, for technical consultation, Dr. Martin Teicher for statistical consultation, and Mrs. Mila Cason for manuscript preparation.

\section{References}

American Psychiatric Association. DSM-III: Diagnostic and Statistical Manual of Mental Disorders. 3rd ed. APA, Washington, DC (1980).

Arana, G.W.. Barreira, P.J., Wilens, T.E., Baldessarini, R.J., Cohen. B., and Lipinski, J. Clinical studies of the dexamethasone suppression test in psychotic illness. American College of Neurops.chopharmacolog." Abstracts, 21, 79 (1982); and Psychopharmacolog. Bulletin. 19(3) (in press).

Baldessarini, R.J. Biomedical Aspects of the Nature and Treatment of Depression. APA Press, Inc.. Washington, DC (1983).

Brock, P. Eldred, E.W., Woisuillo. J.E., Doran, M., and Schoemaker, H.J. Direct solid-phase ${ }^{125}$ I-radioimmunoassay of serum cortisol. Clinical Chemistrl. 24, 1595 (1978).

Carroll. B.J.. Clinical applications of the dexamethasone suppression test for endogenous depression. Pharmacopsychiatre, 15, 19 (1982a).

Carroll, B.J. The dexamethasone suppression test for melancholia. British Journal of PsichiaIr.i. 140, 292 (1982b).

Carroll, B.J., Feinberg, M., Greden, J.F.. Tarika. J., Albala. A., Haskett, R. F., James. N.Mcl., Kronfol. Z.,Lohr, N.. Steiner, M. DeVigne, J.P., and Young, E. A specific laboratory test for the diagnosis of melancholia. Archives of General Psychiatry, 38, 15 (1981).

Farmer. R.W., and Pierce. C.E. Plasma cortisol determination: Radioimmunoassay and competitive protein binding compared. Clinical Chemistry, 20, 411 (1974).

Finklestein. S. Benowitz, L.1.. Baldessarini, R.J., Arana, G.W., Levine, D., Woo, E., Bear, D., Moya, K., and Stoll, A.L. Mood, vegetative disturbance, and dexamethasone suppression test after stroke. Annals of Neurology, 12, 463 (1982).

Jiang, N.S., Machacek, D., and Wadel, O.P. Comparison of clinical assays for serum corticosterone. Clinical Chemistry, 21, 387 (1975).

Kreyszig. E. Introductory Mathematical Statistics. John Wiley, New York, p. 304 (1970). 
Krieger, D.T. Plasma ACTH and corticosteroids. In: De Groot, L.J., Cahill, G.F.. Jr., Odell, W.D., Martini, L., Potts, J.T., Jr., Nelson. D.H., Steinberger, E., and Winegrad, A.I., eds. Endocrinolog.: Chapter 93, Vol. 2. Grune \& Stratton, New York, p. 1139 (1979).

Kumar. M.S.. Safa. A.M.. and Deodhor. S.D. Radioimmunoassay for serum cortisol with 125 I-labeled ligand: Comparison of three methods. Clinical Chemistry, 22, 1845 (1976).

Liddle. G.W. Tests of pituitary-adrenal suppressibility in the diagnosis of Cushing"s syndrome. Journal of Clinical Endocrimolugi and Metabolism, 20, 1539 (1960).

Murphy, B.E.P. Some studies of the protein-binding of steroids and their application to the routine micro and ultramicro measurements of various steroids in body fluids by competitive protein-binding radioassay. Journal of Clinical Endocrinology and Metabolism. 27, 973 (1967).

Ritchie, J.C., and Carroll, B.J. The dexamethasone suppression test in psychiatric diagnosis. Laboratory Management, 20,41 (1981).

Rodbard, D. Statistical quality control and routine data processing for radioimmunoassay and immunoradiometric assays. Clinical Chemistry, 20, 1255 (1974).

Rush, A.J., Giles, D.E., Roffwarg. H.P., and Parker, C.R. Sleep EEG and dexamethasone suppression test findings in outpatients with unipolar major depressive findings. Biological Psychiatry, 17, 327 (1982).

Scientific Products. Immunotrace Solid Phase Cortisol Assay. Technical Information Report, Service Department. Ventrex Laboratories, Portland, ME (1981).

Thijssen, H.H., VanDerBerg, J.H.M., Adlercreutz, H., Gijzen, A.H.J., DeJong, F.H., Meijer, J.C., and Moolenaar, A.J. The determination of cortisol in human plasma: Evaluation and comparison of seven assays. Clinica Chimica Acta, 100, 39 (1980).

Wilens, T.E., Ritchie, J.C., and Carroll, B.J. The comparison of plasma cortisol and corticosterone in the dexamethasone suppression test for melancholia. Psychoneuroendocrinology (in press).

Zar, J.H. Biostatistical Analysis. Prentice-Hall, Englewood Cliffs, NJ, p. 207 (1974). 